\title{
Supporting Information for Anharmonic
}

\section{Molecular Vibrational Probes of Dynamical \\ Organic-Inorganic Interactions in 2D Hybrid Lead lodide Perovskites}

Adedayo M. Sanni, Sydney N. Lavan, and Aaron S. Rury*

Department of Chemistry, Wayne State University, Detroit, MI, USA 48202

E-mail: aaron.rury@wayne.edu 


\section{Contents}

\begin{tabular}{|l|l}
\hline List of Figures & S2
\end{tabular}

\begin{tabular}{|l|l}
\hline List of Tables & S3
\end{tabular}

1 Powder X-ray Diffraction Structural Analysis $\quad$ S4

$1.1 \quad$ Benzylammonium Lead Iodide $\left(\mathrm{BnA}_{2} \mathrm{PbI}_{4}\right) \ldots \ldots \ldots \ldots \ldots$. . . . . . . S4

1.2 Hexyl Ammonium Lead Iodide $\left(\mathrm{HA}_{2} \mathrm{PbI}_{4}\right) \ldots \ldots \ldots \ldots \ldots \ldots$. . . . . . . . S 4

\begin{tabular}{|lll}
2 & Atomic motions in Benzylammonium lead iodide SAQWS S4
\end{tabular}

\begin{tabular}{|lll}
\hline 3 & Hexyl line shape analysis & S8
\end{tabular}

\begin{tabular}{lr}
\hline References & S10
\end{tabular}

\section{List of Figures}

S1 Comparison between measured and Le Bail analysis of powder X-ray diffraction results from $\mathrm{BnA}_{2} \mathrm{PbI}_{4} \ldots \ldots \ldots \ldots \ldots \ldots$

S2 Comparison between measured and Le BAil analysis of powder X-ray diffraction results from $\mathrm{HA}_{2} \mathrm{PbI}_{4} \ldots \ldots \ldots \ldots \ldots \ldots \ldots$

S3 Atomic motions in benzylammonium lead iodide at $169.88 \mathrm{~cm}^{-1} \ldots \ldots$. . . . . . S8

S4 Atomic motions in benzylammonium lead iodide at $173.52 \mathrm{~cm}^{-1} \ldots \ldots$. . . . . . S9

S5 $\quad$ Atomic motions in benzylammonium lead iodide at $174.19 \mathrm{~cm}^{-1}$. . . . . . . . . . S10

S6 $\quad$ Atomic motions in benzylammonium lead iodide at $184.83 \mathrm{~cm}^{-1}$. . . . . . . . . S11

S7 Atomic motions in benzylammonium lead iodide at $187.92 \mathrm{~cm}^{-1}$. . . . . . . . . S12

S8 Temperature dependence of $\Gamma(\omega)$ and $\Delta(\omega)$ when $\left|U_{i j k}^{-}\right|^{2}>\left|U_{i j k}^{+}\right|^{2}$ for $\mathrm{HA}_{2} \mathrm{PbI}_{4}$. S13

S9 Comparison of Calculated Ammonium Bending Raman Peak of $\mathrm{HA}_{2} \mathrm{PbI}_{4}$ when

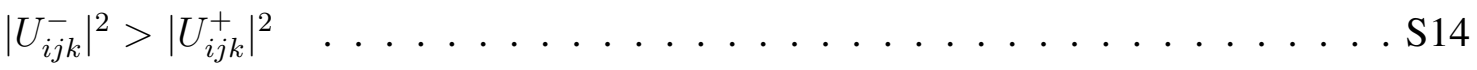


S10 Comparison of Calculated Ammonium Bending Raman Peak of $\mathrm{HA}_{2} \mathrm{PbI}_{4}$ when $\tilde{\nu}_{j}$ $=271 \mathrm{~cm}^{-1}$ and $\tilde{\nu}_{j}=1289 \mathrm{~cm}^{-1} \ldots \ldots \ldots \ldots \ldots$. . . . . . . . . . . .

\section{List of Tables}

S1 $\quad$ Structural Parameters of $\mathrm{BnA}_{2} \mathrm{PbI}_{4} \ldots \ldots \ldots \ldots \ldots \ldots \ldots \ldots$

S2 $\quad$ Structural Parameters of $\mathrm{HA}_{2} \mathrm{PbI}_{4} \ldots \ldots \ldots \ldots \ldots \ldots \ldots$ 


\section{Powder X-ray Diffraction Structural Analysis}

\subsection{Benzylammonium Lead Iodide $\left(\mathrm{BnA}_{2} \mathbf{P b I}_{4}\right)$}

Le Bail method ${ }^{\mathbb{1}}$ of refinement of powder XRD patterns was conducted using the General Structure Analysis System (GSAS-I). ${ }^{[2}$ We refined the following parameters: (1) scale factor; (2) background, which was modeled using a shifted Chebyshev polynomial function; (3) peak shape, modeled using a modified Thompson-Cox-Hasting pseudo-Voigt function; (4) lattice constants; (5) Rigid-body model for N, C and H consistent with alkylammonium and lead iodide; and (6) an isotropic displacement parameter for $\mathrm{C}, \mathrm{H}, \mathrm{N}$ atoms and same parameter for I atoms in $\mathrm{HA}_{2} \mathrm{PbI}_{4}$. In $\mathrm{BnA}_{2} \mathrm{PbI}_{4}$, we did not refine the isotropic displacement paremeter for any atom. The structural parameters from the refinements are shown in Table $\mathrm{S} 1$ and $\mathrm{S} 2$ for $\mathrm{BnA}_{2} \mathrm{PbI}_{4}$ and $\mathrm{HA}_{2} \mathrm{PbI}_{4}$ respectively. Difference curves and Rwp residuals were employed to assess the quality of the refined structural models.

Figure S1 compares the fit found from structural refinement to the experimentally measured XRD pattern. Residual differences are shown in blue. We observe no peaks consistent with a secondary crystalline phase besides the main Pbca orthorombic phase reported previously. ${ }^{3}$

\subsection{Hexyl Ammonium Lead Iodide $\left(\mathrm{HA}_{2} \mathbf{P b I}_{4}\right)$}

Figure S2 visualizes the complete results of the Le Bail structural refinement for $(\mathrm{HA})_{2} \mathrm{PbI}_{4}$. We observe no peak consistent with a crystalline phase other than the $P 2_{1} / a$ monoclinic phase reported previously. 4

\section{Atomic motions in Benzylammonium lead iodide SAQWs}

The graphical illustration corresponding to atomic motions reported in Table 1 of the main manuscript are reported here. These frequencies are in the region of $133 \mathrm{~cm}^{-1}$ plus/minus the uncertainty from the fit in Figure 4 of the main text. We used jmol to visualize the atomic motions as seen in figures 
Table S1: Structural Parameters of $\mathrm{BnA}_{2} \mathbf{P b I}_{4}$ Extracted from Le-Bail refinement Analysis: Space group: Orthorhombic Pbca; $\boldsymbol{a}=9.165(5) \AA, \boldsymbol{b}=8.709(5) \AA, \boldsymbol{c}=28.817(17) \AA, \mathbf{V}=$ $2300(4) \AA^{3} ; \alpha=\beta=\gamma=\mathbf{9 0 . 0 ^ { \circ }}$

\begin{tabular}{|c|c|c|c|c|c|}
\hline Compound & Atom & $x$ & $y$ & $z$ & $U_{\text {iso }}$ \\
\hline & $\mathrm{Pb01}$ & 0.0 & 0.5 & 0.5 & 0.011 \\
\hline & $\mathrm{I} 002$ & 0.20514 & 0.79861 & 0.49248 & 0.014 \\
\hline & $\mathrm{I} 003$ & 0.0431 & 0.47825 & 0.61138 & 0.016 \\
\hline & $\mathrm{N} 004$ & 0.4145 & 0.5678 & 0.58669 & 0.018 \\
\hline & H00A & 0.41103 & 0.55787 & 0.55478 & 0.022 \\
\hline & H00B & 0.4458 & 0.66475 & 0.59428 & 0.022 \\
\hline & H00C & 0.32333 & 0.55206 & 0.5989 & 0.022 \\
\hline & C005 & 0.5204 & 0.4487 & 0.6069 & 0.025 \\
\hline & H00D & 0.47537 & 0.34443 & 0.60524 & 0.030 \\
\hline & H00E & 0.61148 & 0.44729 & 0.5879 & 0.030 \\
\hline & C006 & 0.4823 & 0.4168 & 0.6933 & 0.024 \\
\hline & H006 & 0.40424 & 0.3471 & 0.6866 & 0.029 \\
\hline & $\mathrm{C} 007$ & 0.5569 & 0.4857 & 0.65682 & 0.016 \\
\hline & C008 & 0.7043 & 0.6224 & 0.7127 & 0.030 \\
\hline & H008 & 0.78042 & 0.69449 & 0.71927 & 0.036 \\
\hline & C009 & 0.6677 & 0.5898 & 0.6665 & 0.025 \\
\hline & H009 & 0.71877 & 0.63912 & 0.64147 & 0.030 \\
\hline & C00A & 0.52 & 0.4481 & 0.74 & 0.026 \\
\hline & H00F & 0.46888 & 0.39862 & 0.76504 & 0.031 \\
\hline & C00B & 0.6307 & 0.5504 & 0.7497 & 0.027 \\
\hline & H00G & 0.65717 & 0.57213 & 0.78144 & 0.032 \\
\hline
\end{tabular}


Table S2: Structural Parameters of ( $\mathrm{HA})_{2} \mathbf{P b I}_{4}$ Extracted from LeBAil Analysis: Space group: monoclinic P2 $1 \boldsymbol{a} ; \boldsymbol{a}=8.4828(14) \AA, \boldsymbol{b}=8.6901(18) \AA, \boldsymbol{c}=15.9223(25) \AA, \quad \mathbf{V}=$ $\left.1170.4(5) \AA^{3} ; \alpha=\gamma=\mathbf{9 0}^{\circ} ; \beta=\mathbf{9 4 . 3 1 4 ( 2 6}\right)^{\circ}$

\begin{tabular}{|c|c|c|c|c|c|}
\hline Compound & Atom & $x$ & $y$ & $z$ & $U_{\text {iso }}$ \\
\hline$\left(\mathrm{C}_{12} \mathrm{H}_{32} \mathrm{~N}_{2} \mathrm{PbI}_{4}\right.$ & C1 & 0.96222 & 0.46431 & 0.80411 & 0.25 \\
\hline & H1D & 0.86004 & 0.47356 & 0.83192 & 0.25 \\
\hline & H1E & 1.00208 & 0.35862 & 0.81384 & 0.25 \\
\hline & C2 & 0.93973 & 0.49108 & 0.71104 & 0.25 \\
\hline & H2A & 1.04272 & 0.48814 & 0.68405 & 0.25 \\
\hline & H2B & 0.8948 & 0.59545 & 0.70182 & 0.25 \\
\hline & C3 & 0.83064 & 0.37288 & 0.66883 & 0.25 \\
\hline & H3A & 0.88255 & 0.27086 & 0.67004 & 0.25 \\
\hline & H3B & 0.73298 & 0.36494 & 0.7007 & 0.25 \\
\hline & C4 & 0.79099 & 0.41684 & 0.5782 & 0.25 \\
\hline & H4A & 0.88906 & 0.42244 & 0.54633 & 0.25 \\
\hline & H4B & 0.74201 & 0.51968 & 0.57719 & 0.25 \\
\hline & C5 & 0.67989 & 0.3029 & 0.53456 & 0.25 \\
\hline & H5A & 0.58202 & 0.29639 & 0.56643 & 0.25 \\
\hline & H5B & 0.72906 & 0.19925 & 0.53567 & 0.25 \\
\hline & C6 & 0.63923 & 0.34564 & 0.44313 & 0.25 \\
\hline & H6A & 0.56738 & 0.26976 & 0.41827 & 0.25 \\
\hline & H6B & 0.73578 & 0.34911 & 0.41065 & 0.25 \\
\hline & H6C & 0.58965 & 0.44767 & 0.44161 & 0.25 \\
\hline & N1 & 1.07226 & 0.57418 & 0.84145 & 0.25 \\
\hline & H1A & 1.08407 & 0.55556 & 0.89787 & 0.25 \\
\hline & H1B & 1.03503 & 0.67123 & 0.83324 & 0.25 \\
\hline & H1C & 1.16671 & 0.56452 & 0.81658 & 0.25 \\
\hline I1 & 0.97165 & 0.96748 & 0.80108 & 0.1 \\
\hline & I2 & 0.69394 & 1.19584 & 0.99643 & 0.1 \\
\hline & Pb1 & 1.0 & 1.0 & 1.0 & 0.016 \\
\hline & & & & & \\
\hline
\end{tabular}




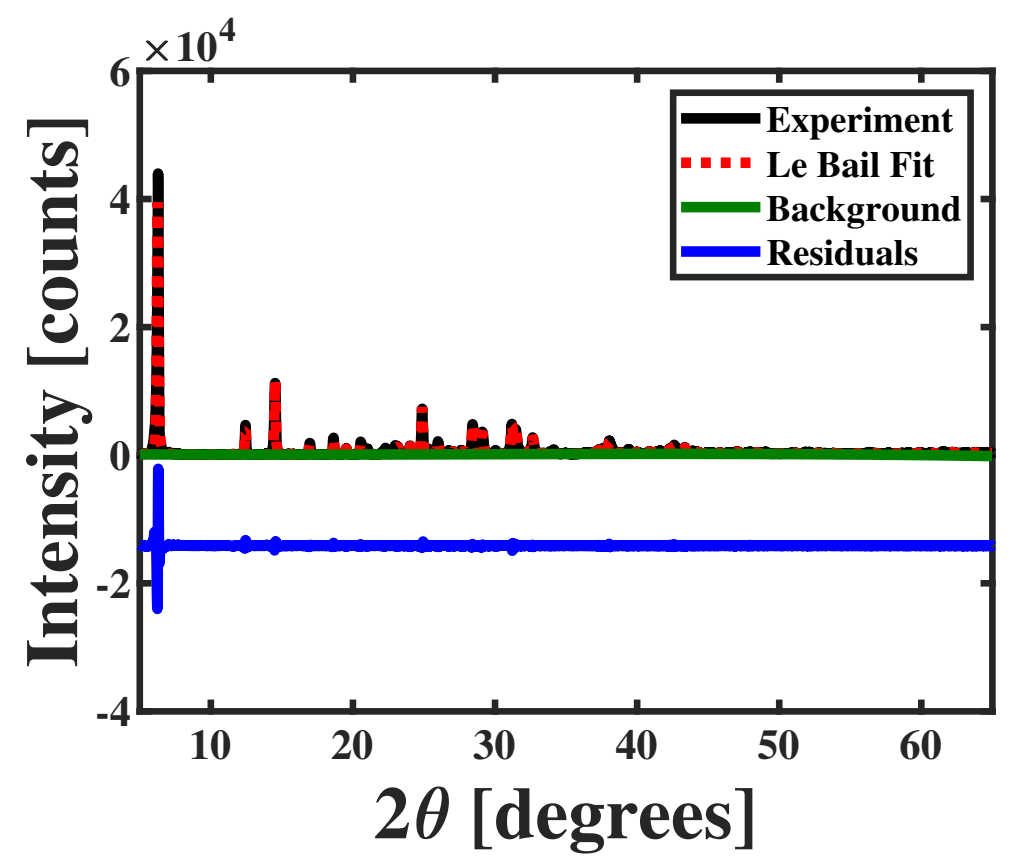

Figure S1: Comparison between measured and Le Bail analysis of powder X-ray diffraction results from $\mathrm{BnA}_{2} \mathrm{PbI}_{4}$ indicating our self-assembled quantum well (SAQW) is phase pure.

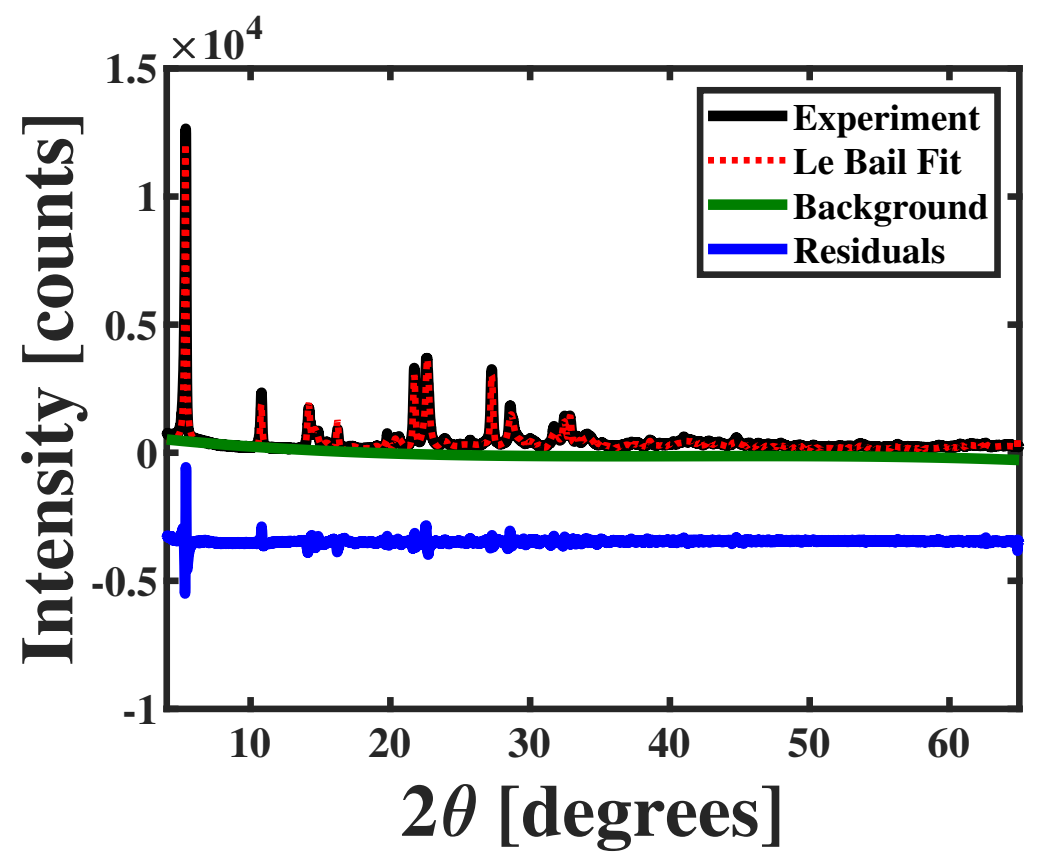

Figure S2: Comparison between measured and Le Bail analysis of powder X-ray diffraction results from $\mathrm{HA}_{2} \mathrm{PbI}_{4}$ indicating our $\mathrm{SAQW}$ is phase pure. 
S4 to S10. The full description of the atomic motions can be found in Table 1 of the manuscript.
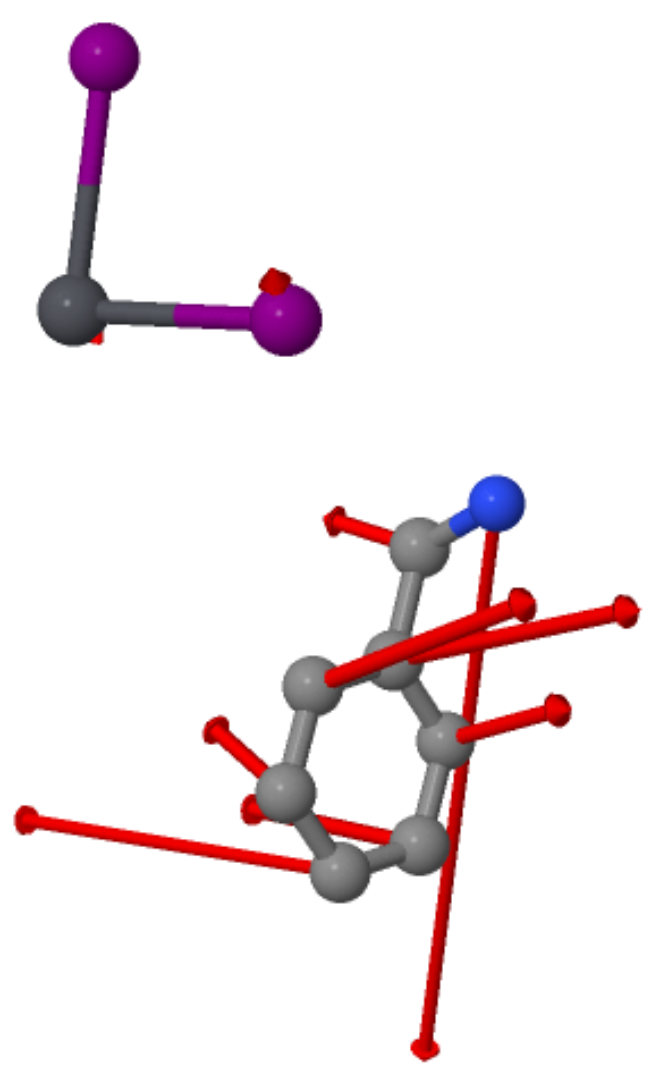

Figure S3: Atomic motions in benzylammonium lead iodide at $169.88 \mathrm{~cm}^{-1}$ showing the out-ofplane tilt of inorganic atoms and benzylammonium wag as described in Table 1 of the main text.

\section{Hexyl line shape analysis}

As reported in the main text of the manuscript, Eq. 2 was used to construct the spectra in Figure 11. In order to calculate the Raman spectrum described by Eq. 2 in the main text, we calculated the the real, $\Delta(\omega)$, and imaginary, $\Gamma(\omega)$, parts of the phonon self-energy as shown in figure 10 we shifted the frequency axis by $39.4 \mathrm{~cm}^{-1}$ as seen in Figure 10. We used the corresponding sums of occupation from different combinations of vibrations in calculating the $\Gamma(\omega)$ and $\Delta(\omega)$ shown in Figure 10. We detailed this algorithm in the main text. We note in the main text that $\left|U_{123}^{-}\right|$ was dropped in Eq. 3 in order to construct the Raman spectra in Figure 11 using $\Gamma(\omega)$ and $\Delta(\omega)$ reported in Figure 10. In the case where $\left|U_{123}^{+}\right|$is significantly lower than $\left|U_{123}^{-}\right|$, we calculated 

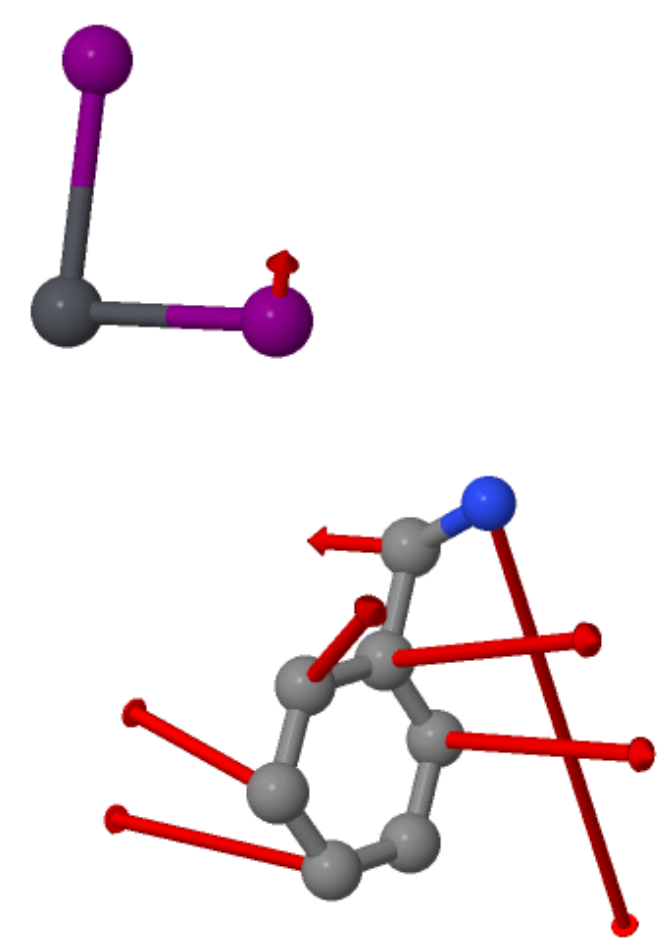

Figure S4: Atomic motions in benzylammonium lead iodide at $173.52 \mathrm{~cm}^{-1}$ showing the octahedral bend of inorganic atoms and benzylammonium wag as described in Table 1 of the main text.

the $\Gamma(\omega)$ and $\Delta(\omega)$, as shown in Figure S8. The panels of Figure S8 and shows the frequency dependence of both the real and imaginary parts of the phonon self energy using $\left|U_{123}^{-}\right|=0.078$ and $\left|U_{123}^{+}\right|=0.0078$. Close inspection of both figures indicate there exists no smooth dependence of $\Gamma(\omega)$ and $\Delta(\omega)$ unlike that seen in Figure 10. When we constructed the Raman spectra using this calculated $\Delta(\omega)$ and $\Gamma(\omega)$ in Figure S8, we obtain the spectra shown in figure S9. Upon inspection of the spectra in figure S9, one observes that the shift, relative intensity and asymmetric line shape reported in Figure 11 of the main text is not reproduced. This analysis must mean that $\left|U_{123}^{-}\right|$play minimal role enough to be dropped from Eq. 5 in the main text. We further showed in Figure 10 that the intensity, line shape and shift comes from the coupling between phonon modes where the occupation number changes significantly. To obtain the two spectra shown in figure S10, we use two modes with less changing occupation number $\left(1289 \mathrm{~cm}^{-1}\right.$ and $\left.271 \mathrm{~cm}^{-1}\right)$ between the temperature ranges to recover a line shape, shift that do not reproduce the spectral properties reported in Figure 11. 

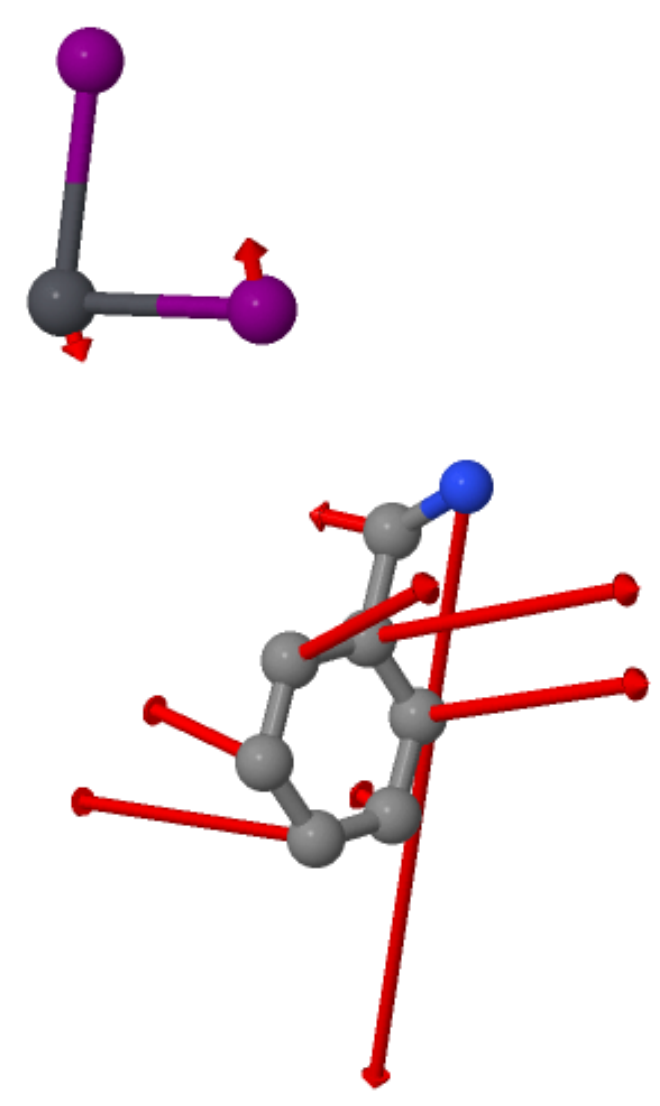

Figure S5: Atomic motion in benzylammonium lead iodide at $174.19 \mathrm{~cm}^{-1}$ showing the in-plane tilt of inorganic atoms and benzylammonium ring distortion as described in Table 1 of the main text.

\section{References}

(1) Bail, A. L.; Duroy, H.; Fourquet, J. Ab-initio Structure Determination of $\mathrm{LiSbWO}_{6}$ by X-ray Powder Diffraction. Mater. Res. Bull. 1988, 23, 447 - 452.

(2) Toby, B. H.; Von Dreele, R. B. GSAS-II: the Genesis of a Modern Open-Source all Purpose Crystallography Software Package. Journal of Applied Crystallography 2013, 46, 544-549.

(3) Kamminga, M. E.; Fang, H.-H.; Filip, M. R.; Giustino, F.; Baas, J.; Blake, G. R.; Loi, M. A.; Palstra, T. T. M. Confinement Effects in Low-Dimensional Lead Iodide Perovskite Hybrids. Chem. Mat. 2016, 28, 4554-4562.

(4) Lemmerer, A.; Billing, D. G. Synthesis , Characterization and Phase Transitions in the 

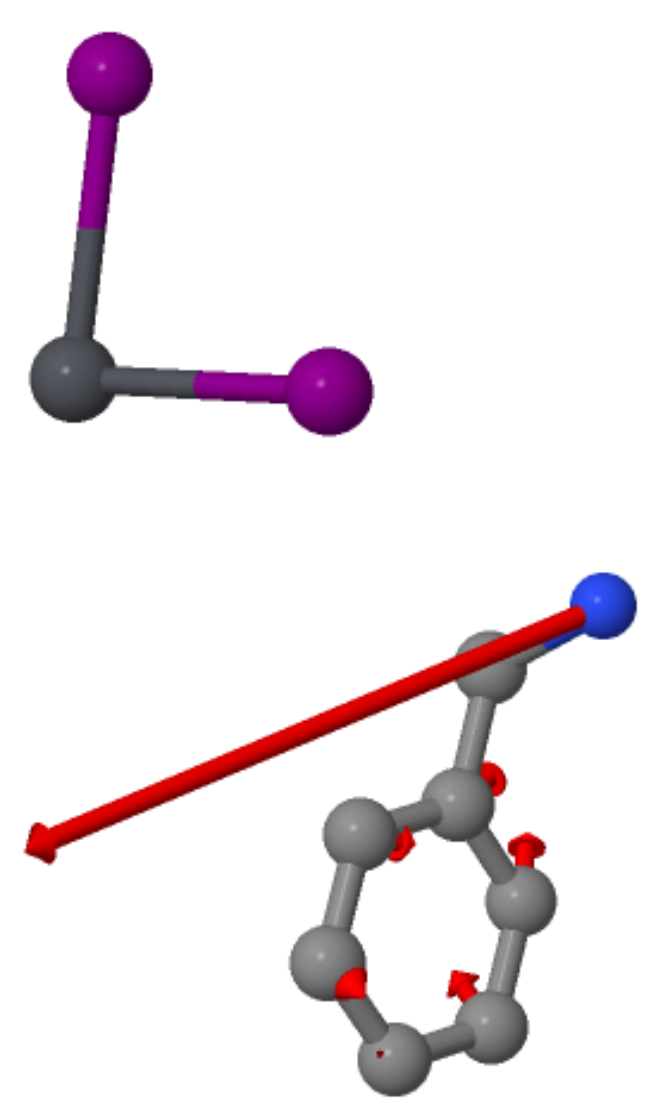

Figure S6: Atomic motions in benzylammonium lead iodide at $184.83 \mathrm{~cm}^{-1}$ showing the out-ofplane tilt of inorganic atoms and benzylammonium libration as described in Table 1 of the main text.

Inorganic-Organic Layered Perovskite-type Hybrids $\left[\left(\mathrm{C}_{n} \mathrm{H}_{2 n+1} \mathrm{NH}_{3}\right)_{2} \mathrm{PbI}_{4}\right], \mathrm{n}=4,5$ and 6 . Acta Crystallographica Section B 2007, 63, 735-747. 

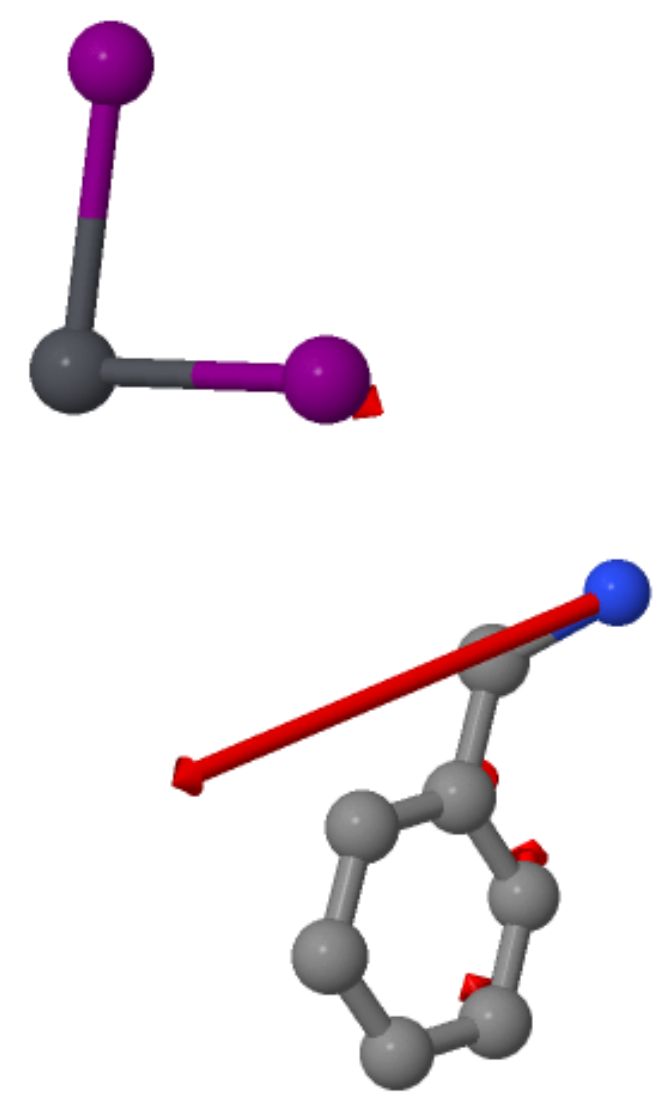

Figure S7: Atomic motions in benzylammonium lead iodide at $187.92 \mathrm{~cm}^{-1}$ showing the in-plane tilt of inorganic atoms and benzylammonium libration as described in Table 1 of the main text. 


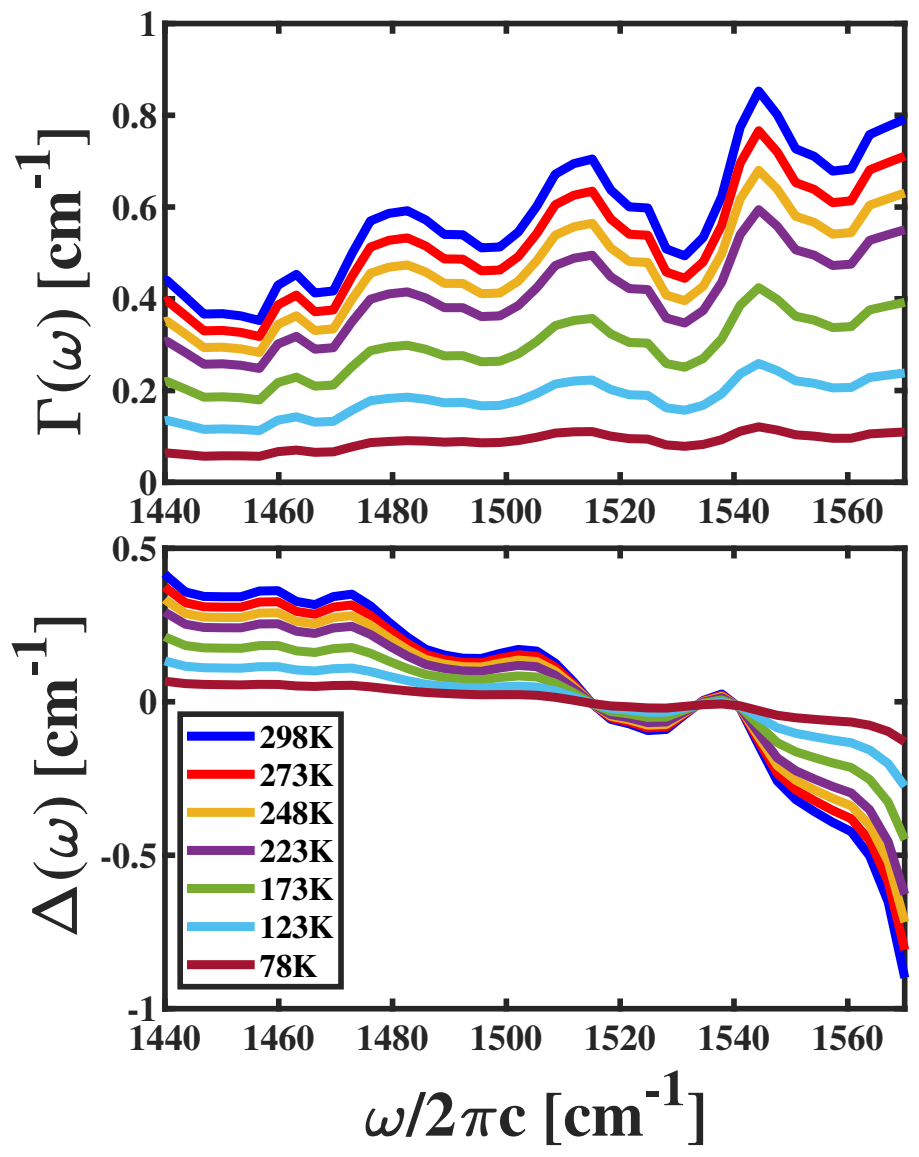

Figure S8: Top panel: Temperature dependence of $\Gamma(\omega)$ constructed from Eq. 3 in the main text using $\left|U_{i j k}^{-}\right|^{2}$ greater than $\left|U_{i j k}^{+}\right|^{2}$. Bottom panel: Temperature dependence of $\Delta(\omega)$ constructed from a Kramers-Kronig transformation of $\Gamma(\omega)$ for the case where $\left|U_{i j k}^{-}\right|^{2}$ greater than $\left|U_{i j k}^{+}\right|^{2}$ in Eq. 3 as explained in the main text. 


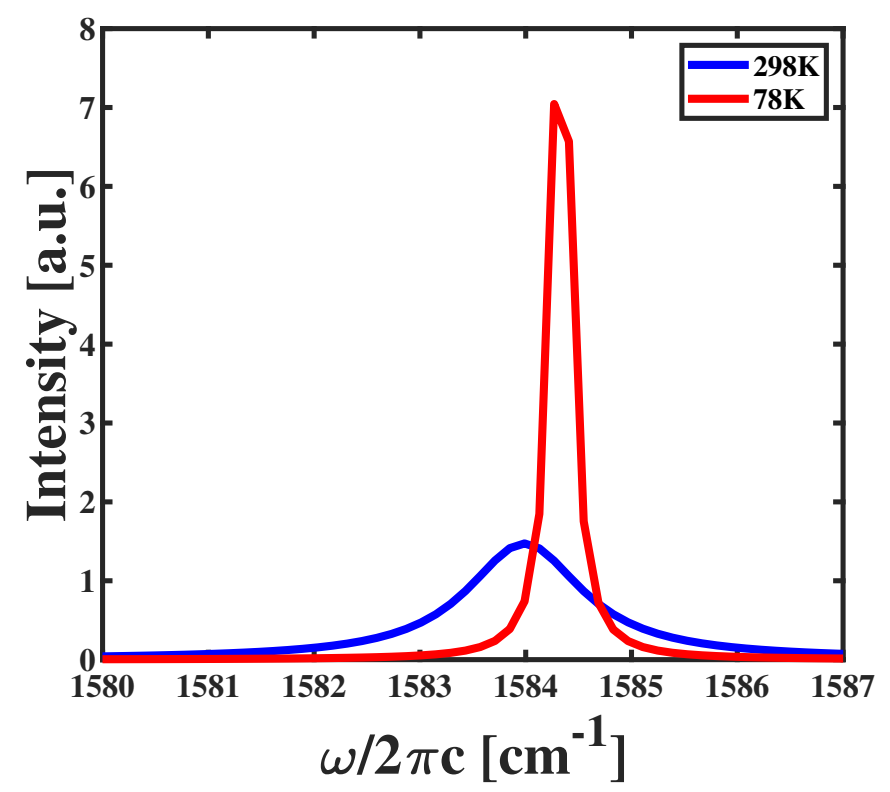

Figure S9: Calculated Raman spectra at $298 \mathrm{~K}$ and $78 \mathrm{~K}$ constructed by using Eq. 2 for $\mathrm{HA}_{2} \mathrm{PbI}_{4}$ With $\left|U_{123}^{-}\right|^{2}$ greater than $\left|U_{123}^{+}\right|^{2}$ in Eq. 3 in the main text.

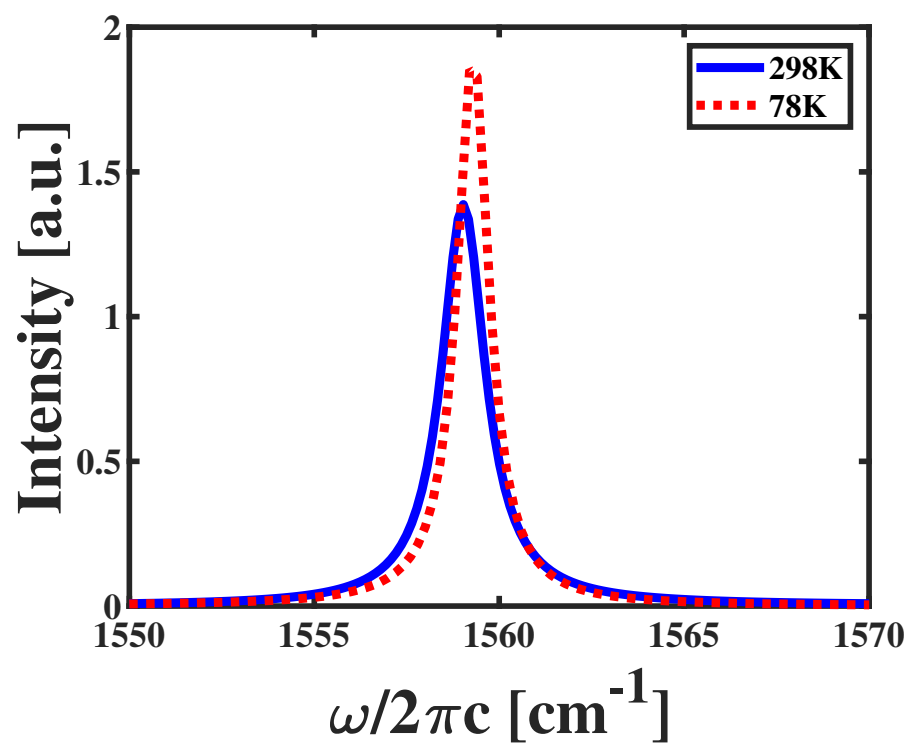

Figure S10: Comparison between calculated Raman spectra at $298 \mathrm{~K}$ and $78 \mathrm{~K}$ in $\mathrm{HA}_{2} \mathrm{PbI}_{4}$ for two phonon modes $1289 \mathrm{~cm}^{-1}$ and $271 \mathrm{~cm}^{-1}$ constructed using Eq. 2 for $\mathrm{HA}_{2} \mathrm{PbI}_{4}$ With $\left|U_{123}^{+}\right|^{2}$ greater than $\left|U_{123}^{-}\right|^{2}=0$ in Eq. 3 in the main text. 